\title{
MIS LECTURAS VIQUIANAS
}

\author{
Fabrizio Lomonaco \\ (Università degli Studi di Napoli "Federico II")
}

RESUMEN: El ensayo reconstruye algunos nudos teóricos e historiográficos fundamentales de la investigación viquiana del siglo XX italiano, con referencia a la escuela histórico-filológica (de Mazzarino a Momigliano), a los estudios sobre la política (Giarrizzo) y a las investigaciones filosófico-jurídicas (de Capograssi a Piovani). Palabras Clave: Vico, $350^{\circ}$ Aniversario, filología, política, derecho, filosofía, historicidad, F. Lomonaco.

\section{My Vichian readings}

ABSTRACT: This essay reconstructs some fundamental theoretical and historiographical knots of Italian Vichian research during the XXth century, with reference to the historical-philological school (from Mazzarino to Momigliano), political studies (Giarrizzo) and philosophical-juridical research (from Capograssi to Piovani).

KEYwORDS: Vico, 350 th Anniversary, philology, politics, Law, philosophy, historicity, F. Lomonaco.

\section{Le mie letture vichiane}

RIASSUNTO: Il saggio ricostruisce alcuni fondamentali snodi teorici e storiografici della ricerca vichiana nel Novecento italiano con riferimento alla scuola storico-filologica (da Mazzarino a Momigliano), agli studi sulla politica (Giarrizzo) e alle ricerche filosofico-giuridiche (da Capograssi a Piovani).

PAROLE ChIAVE: Vico, $350^{\circ}$ Anniversario, filologia, politica, diritto, filosofia, storicità, F. Lomonaco.

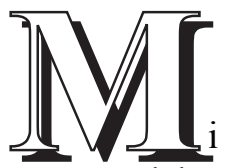

primera orientación en los estudios de interés viquiano debe mucho a un célebre ensayo de Arnaldo Momigliano de 1950 sobre Ancient History and the Antiquarian. En él la idea central de una recuperación de las "técnicas" anticuarias para identificar el verdadero origen de las tradiciones y combatir los peligros del "pirronismo" postcartesiano en los estudios sobre Roma antigua (de La Mothe le Vayer a Bayle, de Huet a Hardouin, de Fréret a De Beaufort) se fundaba sobre la denominada capacidad de los anticuarios de dedicar particular atención a 
la distinción entre "fuentes originales y derivadas". El objetivo de la investigación era el análisis de la tradición literaria y no literaria (arqueológica y paleográfica, numismática y epigráfica), objeto de creciente interés a la luz del "conflicto" entre erudición y filosofía en los siglos XVII y XVIII, de la revolucionaria «combinación entre historia filosófica y método anticuario» de Winckelmann e Gibbon, hasta el siglo XIX, cuando «no estaba ya justificado hacer una distinción entre estudios anticuarios y estudios históricos». ${ }^{1}$

La fuerza de las «consecuencias de la renovación de la historia de los derechos antiguos $\rangle^{2}$ de Momigliano ha alimentado directamente mis investigaciones en torno a la fortuna de un documento de los más emblemáticos de la historia del derecho romano antiguo: la inscripción de la Lex regia de imperio Vespasiani que, anotada sobre una lámina de bronce, reproduce la parte final de un acto aprobado por el pueblo y por el senado romanos entre el 69 y el 70 d.C., para legitimar las potestates reconocidas por Vespasiano con ocasión del ascenso al trono. Destinada a comprometer algunos de los mayores representantes holandeses de la escuela filológica e histórico-jurídica, el análisis de este documento -no siempre valorado por la cultura histórico-filosófica moderna, sobre todo italiana, con la excepción de Gravina $^{3}$ - no fue solo una ejercitación escolástica de regulae literario-retóricas. La sustancia del nuevo enfoque (y este es uno de los hilos conductores del análisis iniciados por mí sobre Gronovius y Huber, Perizonio y Le Clerc hasta Noodt y Barbeyrac) ${ }^{4}$ no estaba en el retorno a los clásicos o en la transformación de los objetos de la indagación histórica, sino en un enfoque distinto del análisis de los problemas afrontados a la luz del nuevo y complejo entramado de derecho, erudición anticuaria y política. La Lex se volvía un "lugar" históricamente definido y útil para iniciar indagaciones sobre los orígenes y el carácter del absolutismo moderno, sobre las razones de posibles conflictos entre auctoritas y libertas, sobre nuevas relaciones entre jurisprudencia y poder. Con diferentes soluciones al tema del origen de la potestas y a las relativas definiciones del status naturae, de "origen" y "naturaleza" de los contratos, se iniciaba una significativa revisión de la antigua pedagogía sobre los arcana imperii y de la entre tanto inadecuada "preceptística". Con

1. A. Momigliano, «Ancient History and the Antiquarian» (1950), tr. it. de F. Codino, en ID., Sui fondamenti della storia antica, Einaudi, Turín, 1984, pp. 4, 33 ss., 39, 5.

2. Me refiero a la conferencia inaugural al primer congreso internacional de la Società italiana di storia del diritto (1963) sobre «Le conseguenze del rinnovamento della storia dei diritti antichi» (1964), luego en ID., Sui fondamenti della storia antica, cit., p. 185.

3. Véanse mis investigaciones incluidas en la monografía sobre Filosofia, diritto e storia in Gianvincenzo Gravina, presentación de Paolo Rossi, Edizioni di Storia e Letteratura, Roma, 2006. Para un balance crítico de las temáticas examinadas a continuación, cfr. mi «Filologia, diritto e storia», en Storicismo e storicismi, a cargo de G. Cacciatore y A. Giugliano, Bruno Mondadori, Milán, 2007, pp. 324-362.

4. Lex Regia. Diritto, filologia e fides historica nella cultura politico-filosofica dell'Olanda di fine Seicento, Guida, Nápoles, 1990 y «Holland between the 17th and 18th Centuries», en New Studies on Lex Regia. Right, Philology and Fides Historica, P. Lang, Berna, 2011. 
cuidada sensibilidad crítica, el marco de referencias de los historiadores y los juristas holandeses se complicaba en muchas direcciones, interpretando (Huber) las tesis de Grocio con y contra las de Bodin y Althusius, de Hobbes y Spinoza, en la utilización de un modelo, el del derecho "pretorio" que invitaba, en sintonía y en polémica con Perizonio, a reflexionar sobre el problema, totalmente moderno, de la relación entre la "equidad civil" y la "equidad natural", a oponer a la antigua ratio politica de Statu, una distinta, nueva y justa exigencia de ratio, surgida como aequitas civilis sobre el viejo tronco de la "equidad natural" e incluida en el orden de la historia. En tal contexto teórico-doctrinal -destinado a ser desarrollado por la posterior propuesta "política" de Vico en el De ratione (su obra "más napolitana", pero la que se identifica con la gran y conocida querelle europea en torno al método, desde el admirado Bacon hasta las voces de Galileo y Descartes) ${ }^{5}$ - la otra cara de la antigua razón de Estado, el "pirronismo histórico" y su objetivo de invalidar el nexo causal entre los hechos y sus motivos no tuvieron más ninguna razón de ser.

Para el estudio de estas temáticas me vi beneficiado de la más actualizada bibliografía crítica que, también por razones profesionales, he comenzado a frecuentar, la de la mitad de los años Ochenta, en calidad de investigador del Consiglio Nazionale delle Ricerche, asignado al napolitano "Centro di Studi Vichiani”, el gran taller de investigaciones, querida en 1968 por el fundador del "nuevo curso" de estudios, Pietro Piovani, y dirigida por más de treinta años por Fulvio Tessitore. ${ }^{6}$ En una amplia y variada serie de lecturas y de exploraciones, de sondeos y de investigaciones, emergía una primera posible orientación gracias, sobre todo, a los escritos de Giuseppe Giarrizzo, a quien he leído y releído en la recopilación (no por casualidad publicada en Nápoles) de 1981 sobre Vico, la politica e la storia. No creo exagerar al decir que ellos, con y a través de Vico, han transformado el modo de pensar la historia de la cultura filosófica e historiográfica del Siglo Dieciocho napolitano y europeo a la luz de la relación entre cultura iluminista y mundo dieciochesco (como dice un ensayo de 1956), un nudo temático fundamental, este, nutrido de "historicismo", pero reflejado en una problemática muy distinta de la crociano-nicoliniana y relevante para el entrelazamiento investigado entre «historia de los intelectuales meridionales»e «historiografía viquiana», que parece un «riesgo obligado», impuesto por la misma «tradición meridional». ${ }^{7}$ Así,

5. Ver B. DE GIOVANNI, «Il "De nostri temporis studiorum ratione" nella cultura napoletana del primo Settecento», en Omaggio a Vico, a cargo de P. Piovani, Morano, Nápoles, 1968, pp. 186 ss. y 191. A propósito, permítaseme remitir a mi reciente recopilación de estudios sobre I sentieri di Astrea. Studi intorno al Diritto universale di Giambattista Vico, Edizioni di Storia e Letteratura, Roma, 2018, cap. II.

6. «Pietro Piovani e il Centro di studi vichiani», Bollettino del Centro di studi vichiani, XXX, 2000, pp. 153-175 (de ahora en adelante BCSV); trad. española en Cuadernos sobre Vico, nn. 13-14,2001-2002, pp. 139-152.

7. G. GiarRizzo, «Presentazione» de ID., Vico, la politica e la storia, Guida, Nápoles, 1981, p. 7. Cfr. F. Lomonaco, «Vico e il Settecento europeo secondo Giuseppe Giarrizzo», BCSV, XLVII, 2017, pp. 27-50. 
el historiador siciliano -que había privilegiado el discurso sobre la historia italiana y europea como lugar de la compleja intersección entre «el poder y el condicionamiento social»; ${ }^{8}$-encontraba el anticuario y el filólogo clásico de las primeras experiencias de investigación, impaciente frente al historicismo absoluto y la historia ético-política, porque se formó en la escuela del «historicismo de los historiadores» ${ }^{9}$ una definición, esta última, atribuida a su maestro, el gran anticuario de Catania, Santo Mazzarino, historiador del fin del mundo antiguo y del bajo imperio, de la Decadenzidee en la historia antigua y moderna. En tal horizonte, la relación de Vico con sus fuentes, también con las holandesas, era considerada en términos decisivamente distantes de la tradición historiográfica. No por casualidad, en efecto, Giarrizzo preparaba un listado de cuestiones todavía dignas de profundización, subrayando la necesaria rvisión de la entera problemática del Diritto Universale «cuya deuda con Grocio y con el debate Grocio-Gronovio es inmenso». ${ }^{10}$

Las temáticas así individualizadas y las perspectivas de investigación surgidas me convencieron de la utilidad de recorrer este camino que conectaba al historiador siciliano al autor del Pensiero storico classico, llegando autónomamente a Vico y a su mundo entre análisis y derecho, antes de dedicar atención, en 1979, a Vico, Holland and Modern Conceptions of History. Por la novedad y las características del "nuevo curso" de los estudios, un discurso sobre Vico y los holandeses de los siglos XVII y XVIII no podía ya ser genérico. En el amplio y sugestivo cuadro temático, siempre críticamente vigilado por el historiador del "fin del mundo antiguo", la imagen de Vico era eficazmente restituida en sus rasgos a los tiempos de la gran cultura jurídica-filosófica moderna y, en particular, de la Holanda de Gronovius y Huber, de Noodt y Bynkershoek, confrontados con Hobbes y Grozio a propósito de las relaciones entre derecho romano y ius naturale, mencionados por la discusión sobre la prerrogativa de la patria potestas. ${ }^{11} \mathrm{Se}$ trataba, por otra parte, de señalar coincidencias temáticas (el heroísmo de los pueblos primitivos y la rigidez de la legislación y de la moral romanas arcaicas) que sobreentendían un trabajo común, digno de ser comprobado en sus efectivas dimensiones y circulaciones, contribuyendo a la identificación de las fuentes y de los límites reales de la meditación viquiana sobre la historia antigua, y sobre la romana en particular. No obstante, la investigación de rastros del filósofo napolitano en los estudiosos holandeses, distantes en el tiempo y en el espacio, no se resolvía ni intenta-

8. Así F. Tessitore, «Presentazione» de G. Giarrizzo, La scienza della storia. Interpreti e problemi, a cargo de F. Tessitore, Liguori, Nápoles, 1999, p. XII.

9. Cfr. G. GiarRizzo, «Lo storicismo degli storici nel secondo Novecento», en I percorsi dello storicismo italiano nel secondo Novecento, a cargo de M. MartiRano y E. Massimilla, Liguori, Nápoles, 2002, pp. 275-292.

10. ID., «La politica di Vico», en ID., Vico, la politica e la storia, cit., p. 98.

11. S. Mazzarino, Vico, «Holland and Modern Conceptions of History», Quaderni Catanesi di Studi Classici e Medievali, I, n. 2, 1979, especialmente pp. 360-361. 
ba resolverse en una suerte de búsqueda de predecesores de dudosa utilidad. El mito neoidealista del "aislamiento" no era sustituido por el igualmente insuficiente de la mera dependencia o de la simple repetitividad de módulos y problemas más o menos propios de Vico. Este es un hombre del Siglo Dieciocho, para ser colocado junto a Godefroy y a Gibbon, los dos autores admirados por Mazzarino y por Momigliano (que privilegiaba a Gibbon), pero por razones de teoría y de historia de la historiografía claramente diferenciados. Del historiador de lo antiguo Fra Oriente e Occidente, lector de Ortega y Gasset y de Bergson (este último contrapuesto a la fe hegeliana en la racionalidad de lo real sin residuos) he captado la sensibilidad a la cuestión de la crisis identificada como generadora de lo nuevo, abierta constitutivamente a la vida, según la teoría y la práctica de la "crítica" de la ciencia; lo que esta

«pareció enseñar a los filósofos, la filosofía de la acción quiere enseñárselo a los historiadores: el "impulso vital" pareció inexplicable sin este anhelo de lo nuevo y de la "época" lo sustituye y en cierto modo destruye. También la historia, como la naturaleza, procedería por saltos».

Lo documentaba la antigua Roma en la edad del decenvirato legislativo y del tribunado militar con la "equiparación de los órdenes" y la resistencia de las curie y de las centurie:

«En Roma confluían, al mismo tiempo, evolución y revolución. Esto fue verdaderamente el "milagro" romano. Esto es también una enseñanza para nosotros. La historia no es historia de destrucciones que no reconstruyan, de conservaciones que no se renueven. Como el Estado romano, ella tiene dos caras: la revolución y la continuidad; el eterno renovarse y el eterno durar».

Filosofía de la acción y dialéctica de crisis y conservación están en el fundamento de una lectura del lento y complejo pasaje de la monarquía al estado republicano, que, realizada en la inmediata posguerra italiana, contiene también un llamamiento político a la burguesía de hacerse clase dirigente, considerado que

«todo gran organismo estatal obedece a una exigencia y (aquí tampoco nos escandalizamos por la palabra) a una ley: las clases superiores no pueden vivir aparte de los fermentos históricos elaborados por las inferiores. A esta "ley" ha obedecido también Roma»..

12. ID., Dalla monarchia allo stato repubblicano. Ricerche di storia romana arcaica, G. Agnini editore, Catania, s. a. (pero 1945), pp. 92, 224-225 (cfr. también p. 124). 
Esta crítica de la sociedad burguesa, inspirada en el catolicismo originario (hostil al liberalismo y al catolicismo liberal) y llegada, en un segundo momento, al comunismo del historiador-anticuario, me ha permitido "actualizar" en sentido crítico la lección viquiana y converger sobre otra interpretación -también ella distante del crocianismo- de la «filosofía de la acción» y de la dialéctica entre crisis y continuidad en el curso histórico: la «filosofía del derecho» de Giuseppe Capograssi, oportunamente mencionada por Tessitore a propósito de la lectura mazzariniana. ${ }^{13}$ Con las tesis sobre la nueva relación entre filosofía, ciencia e historia, tratadas en las conocidas páginas de Il problema della scienza del diritto (1937), estamos dentro del estilo de una gran lección, dedicada primera y diversamente por Mazzarino a confrontarse críticamente con los modelos culturales del neoidealismo italiano. ${ }^{14}$ No es posible aquí reconstruir la génesis y el desarrollo de tal confrontación, ni es útil imitar la finísima reconstrucción que Piovani ha ofrecido del itinerario de su admirado maestro. Lo que interesa subrayar aquí de la obra de 1937, la más amplia y orgánica del filósofo de Sulmona, ${ }^{15}$ es la atención dedicada al devenir de la historia en términos que, también en este caso, vuelven compatibles evolución y revolución, conservación y movimiento. En Capograssi como en Mazzarino, pero con resultados netamente diferenciados, esta lectura del devenir de la historia se conecta directamente con el gran tema viquiano de la posible corrupción de la acción. La actualidad del filósofo napolitano está en mostrar que con rupturas y crisis el conflicto posible en la historia humana, intrínsecamente dramática y agonística, pone las condiciones de emergencia del novum en la experiencia, contrapuesta a la pureza ascética de toda síntesis absoluta y definitiva, dirigida hegelianamente a superar la irregular historia humana. Para Capograssi es importante la función de atribuir a lo negativo de la decadencia, cual complemento de la acción y de su proceso de vida, respetuoso de la ley de la providencia, una

«ley de necesidad, por la cual el individuo debe arribar al extremo de su experiencia; hasta la catástrofe [...] En este último punto se recrea la experiencia de muerte de la que nace el pensar humano, el mundo humano».16

13. F. Tessitore, «Sul Vico di Santo Mazzarino» (1990), luego en ID., Contributi alla storia e alla teoria dello storicismo, V, Edizioni di Storia e Letteratura, Roma, 2000, pp. 225-227 (luego aparecido [con muchos errores] en ID., Mazzarino e lo storicismo degli storici, Facoltà di Lettere e Filosofia, Catania, 2003, pp. 60-63).

14. ID., «Filosofia del diritto, dogmatica e scienza romanistica» (1964), luego (con el título «Pietro De Francisci tra storia e sociologia») en ID., Contributi alla storia e alla teoria dello storicismo, vol. V, cit., pp. 193, 195-196.

15. Cfr. P. PIOVANI, «Introduzione» a G. CAPOGRASSI, Il problema della scienza del diritto, nueva edición a cargo de P. Piovani, Giuffrè, Milán, 1962 (desde ahora se cita con la sigla $P S D$, seguida de la indicación de las páginas relativas a la reimpresión en G. CAPOGRASSI, Opere, vol. II, Giuffrè, Milán, 1959), p. V. De este mismo autor, véase el conocido y magistral perfil Itinerario di Giuseppe Capograssi, Giuffrè, Milán, 1956.

16. G. CAPOGRASSI, «L'attualità di Vico» (1943), luego en ID., Opere, cit., vol. IV, p. 401. Sobre el tema son fundamentales las páginas de P. PIOvANI, «Capograssi e Vico», BCSV, VI, 1976, pp. 198-202. 
Con ello se refuerza el valor de la experiencia individual, considerada irreductible a la vida del espíritu absoluto y universal. El problema de la existencia universal y el problema de la historia no son estadios transitorios que se resuelven nada más que en sí, en una verdadera sustancia única, sino resultados constitutivos del mundo concreto del hombre. Coherente con la advertida herencia viquiana, la exigencia de individualidad como función y nunca como sustancia se conjuga con lo que en el mundo del derecho es íntima coherencia, «íntima totalidad organizada en torno a la idea humana». Se llega, así, al corazón de toda la experiencia jurídica, cuando la ciencia revela su auténtica razón de ser en el querer aquella profunda unidad de vida, presente en el ritmo de todas las determinaciones históricas. Puesta en relación con la historia, la ciencia no es la historia, es la formación de un pensamiento dirigido a encontrar «el elemento universal del cual la nueva particular formación no es más que una particular posición». Interviene la preocupación teórica de evitar el solipsismo y toda dispersión de la realidad individual en el vago fluir de un atomismo incomunicante, es una preocupación que llega a negar viquianamente incluso el «derecho a la soledad» ${ }^{17}$ en la experiencia jurídica que es intrínsecamente «colectivismo», la única condición posible de construcción, en una perspectiva no ya idealista, del sistema de lo real como crítica y análisis de la experiencia común, para parafrasear un conocido texto capograssiano de 1931. Por lo tanto, se ha dicho sumamente bien que el historicismo implícito en la ciencia del derecho es «universalizante y uniformante», en el cual las razones del sujeto agente son salvadas por el teorizado nexo fundamental entre las «categorías profundas» de la humanidad y la trascendencia de lo Absoluto con la mediación de las categorías, conjuntamente históricas y metafísicas, de la ley moral. ${ }^{18}$

Con la lección de Capograssi y partiendo del De uno, de sus interesantes asimetrías con la Scienza nuova, he intentado articular un discurso sobre el primer libro del Diritto universale que marca, a mi juicio, un giro en la meditación viquiana, un momento relevante en la redefinición de la relación entre la metafísica y las cuestiones filosóficas del derecho. Me he convencido, en efecto, de que la metafísica del derecho para sostenerse tiene necesidad de una teoría de la justicia. El interés por el mundo del ius (y esta es una de las tesis que sostengo y de perspectiva de estas reflexiones mías) no es banalmente la vía de acceso a la historia (a las Scienze nuove) según un modelo de desarrollo ascendente y de progresiva positividad. Es, en cambio, la puesta en el centro de la reflexión filológico-filosófica de aquella necesidad de eticidad a la que Descartes y los cartesianos meridionales habían dado respuestas "provisorias" pero no exhaustivas, considerando que, observa Vico en la autobiografía, el estudio de las pasiones «sirve más a la medicina que

17. G. CAPOGRASSI, $P S D$, pp. 556, 581, 623, nota.

18. Así: P. PIOvANI, «Introduzione», cit., p. XXXI. 
a la moral». ${ }^{19} \mathrm{El}$ derecho ilumina el horizonte ético de la unidad intensiva del saber como disciplina y fidelidad a la vida: es el principio de medida de la acción no como disposición arbitraria, sino como acto de vida en la vida de los actos de la experiencia humana. Pero la justa aspiración al honeste vivere en libertad es dura de perseguir, porque el pecado original del hombre complica la relación de lo individual con lo universal. Aquí vive la marca distintiva de la ética moderna, una ética del hombre adversa al iusnaturalismo antiguo y moderno, polémica contra toda axiología abstracta en vista de síntesis pacificadoras que el individuo quisiera alcanzar, pero no puede $y$, sobre todo, no debe querer sin anular los propios límites antropológicos y aniquilar el sentido de su existir histórico, signado por el dato de la finitud. Vico intenta la vía de la ética para explicar la vida del derecho en la societas, tomando conjuntamente la idea del derecho como justicia y el criterio de certeza de su hacerse sin salvación predeterminada en todas las objetivaciones de la historia. ${ }^{20}$ Experiencia y ciencia del derecho delatan una original, compleja ambivalencia, del momento que se imponen al individuo a realizarse exteriorizándose en las dimensiones de lo común y de lo colectivo, plantean, sin resolverla, una tarea ulterior: la salvación de la acción individual en la «teología civil razonada de la Providencia», que no resuelve su insuperable dramaticidad del nuevo «misterio» del Dios cristiano de Vico, cercano al Deus absconditus de Pascal, presente en la «plegaria» del hombre en cuanto necesitado de su pietas. ${ }^{21}$

Juzgada por Maquiavelo como el más artificial de los instrumentos para la impostura sacerdotal y el ejercicio del poder, la religión deviene, en Vico, elemento de natural cohesión social, que incrementa la espontánea necesidad de la vida social, radicándose en las instituciones fundantes de la civitas, «tres fontes seu tria capita universi romani iuris» (patria potestas, connubium y nexum), cada uno «impregnado de religión». ${ }^{22}$ La teoría de un derecho universal se cualifica para el empleo del ius en función de una universalización de lo religioso, más que de su exclusión. He insistido mucho sobre el valor de la religión cristiana como dimensión ética e histórica constitutiva del hombre, enfatizando el tema del pudor que intenta la unidad de la mente y el cuerpo y conoce como su consecuencia «la reverencia del sentido común» entre la ignorancia de lo verdadero y la conciencia del pecado. Es aquí donde radica el sentido del derecho como responsabilidad del hacer, como medida de la utilidad en cuanto principio de acción y experiencia, generador

19. Vita di Giambattista Vico scritta da se medesimo [1723-1728], luego con la reimpresión facsimilar del original [y la trad. it. de la edición Fubini], al cuidado y con introducción de F. LomonAco, postfacio de R. Diana y contribución bibliográfica de S. Principe, Diogene edizioni, Nápoles, 2012, p. 49.

20. Cfr. F. Lomonaco, «Derecho, Ética e Historia en el De uno», Cuadernos sobre Vico, 30-31, 2017, pp. 179-192. 21. G. CAPOGRASSI, «Introduzione alla vita etica» (1953), luego en ID., Opere, cit., vol. III, pp. 103, 167.

22. G. VICO, Liber Alter qui est De Constantia jurisprudentis (1721), en ID., Opere giuridiche, a cargo de P. Cristofolini, Sansoni, Florencia, 1974, p. 696. Cfr. F. Lomonaco, I sentieri di Astrea. Studi intorno al Diritto universale di Giambattista Vico, cit., cap. IV-VII. 
de relaciones intersubjetivas. La acción humana no es fragmento inconexo ni pura teoría separada del tiempo, sino contenido constitutivo de la experiencia histórica de los hombres en la cual nada puede decirse cerrado y concluido por siempre.

[Traducción del italiano por Alberto Mario Damiani]

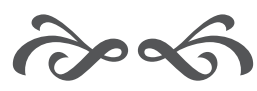


<smiles>[As]</smiles> 